\title{
Adhesion Assessment Between Composites Using Three Different Protocols
}

\author{
RAUL GHIURCA ${ }^{1}$, SMARANDA BUDURU ${ }^{2 *}$, MARIUS BUD ${ }^{3}$, RARES BUDURU ${ }^{1}$, \\ CRISTIAN CULCITCHI ${ }^{1}$, MANUELA MANZIUC ${ }^{2}$, LAURA ZAHARIA ${ }^{4}$, ANCA MESAROS ${ }^{5}$ \\ ${ }^{1}$ STOMESTET Dental Clinic, 68A Calea Manastur, 400335, Cluj Napoca, Romania \\ ${ }^{2} \mathrm{UMF}$ „IuliuHațieganu“ ClujNapoca, Department of Prosthodontics, 32 Clinicilor Str., 400006, Cluj Napoca, Romania \\ ${ }^{3}$ UMF „IuliuHațieganu” ClujNapoca, Department of Dentistry, Endodontics and Oral Pathology, 33 Calea Motilor, 400001, \\ Cluj Napoca, Romania \\ ${ }^{4}$ Emergency Clinical Hospital of ClujNapoca, Pediatric Dentistry, 3-5 Clinicilor Str., 400006, ClujNapoca, Romania \\ ${ }^{5}$ Iuliu Hatieganu University of Medicine and Pharmacy, Faculty of Dental Medicine, Department of Propedeutics and \\ Dental Aesthetics, 32 Clinicilor, 400006, Cluj Napoca, Romania
}

\begin{abstract}
The main purpose of this study is to evaluate three different adhesiveprotocols between two composites. We used 60 composite specimens (Kerr's Herculite XRV Ultra), randomly divided into 3 equal experimental groups, in which adhesion was performed using different protocols: Group 1 ( $n=$ 20) surface preparation with a $1.4 \mathrm{~mm}$ cylindrical diamond bur (Kerr Dental, FG503C-5) + etch and rinse technique in 2 steps; Group $2(n=20)$ surface preparation with a $1.4 \mathrm{~mm}$ cylindrical diamond bur (Kerr Dental, FG503C-5) + Al2O3 (Zhermack Dental) sandblasting + etch and rinse technique in 2 steps; Group $3(n=20)$ surface preparation with a $1.4 \mathrm{~mm}$ cylindrical diamond bur (Kerr Dental, FG503C-5) + glycine (EMS) sandblasting + etch and rinse technique in 2 steps. Adhesion assessment was made by measuring tensile strength with a universal testing machine, the INSTRON 3343 (Instron ${ }^{\circledR}$, USA). At the end, the results were statistically compared using the ANOVA test. Group 3 (glycine protocol) had the greatest values in terms of tensile strength.
\end{abstract}

Keywords: glycine, sandblasting, composite, tensile strength

\section{Introduction}

Diacrylic composite resins (DCR) represent a complex three-phase chemical system consisting of an organic phase, an anorganic phase and bonding agents (silanes).

The organic phase represents the phase which through polymerisation creates a solid mass that adheres to dental tissues. It absorbs water and it is responsible for the aging effect and chromatic changes of the material. The organic phase consistsof:

-basic monomers - dimethacrylic compounds with large molecular mass (Figure 1).

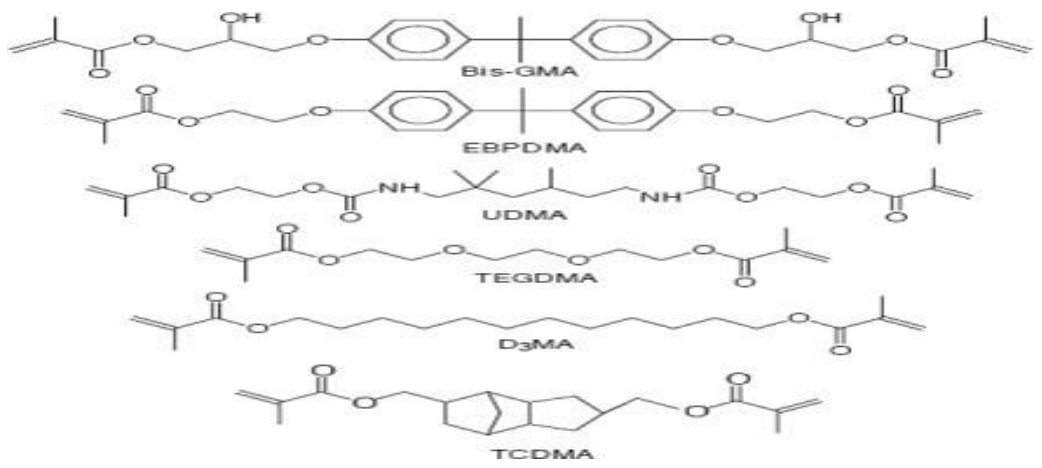

Figure 1. Chemical formula of the basic monomers

\footnotetext{
*email: smarandabuduru@yahoo.com
} 
-dilution monomers- low molecular weight compounds that give the viscosity degree to the composite (Figure 2)
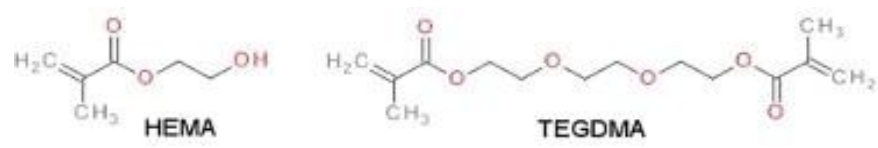

Figure 2. Chemical formula of the dilution monomers

-polymerisation reaction initiation system- in case of self-curing resins, it is an initiator based on organic peroxide (POB) and an accelerator represented by a tertiary aromatic amine (N, Ndiethanol p-toluidine) and for the photopolymerisable ones: CQ and N,N-dimethylaminoethylmethacrylate.

-additives

-polymerisation inhibitor (hydroquinone)- ensures long-term preservation ofDCRs

-UV radiationstabilizers

-pigments anddyes

The anorganic phase (30-90\%) was introduced in the composition of DCR for increased fracture resistance, translucency, chromatic stabilization, decreased polymerisation contraction, viscous growth and radio-opacity [1].

Composite resins are widely used today in dental practice. This evolution has led to the development of different types of composites [2,3]. They are used for both direct (composite fillings) and indirect restorations (inlays, onlays etc.) or in prosthetics (veneers, dental bridges, crowns). However, an annual failure rate of 0-9\% in the direct restoration technique has been reported [4]. The maximum longevity over 10 years is $74.2 \%$ [5]. Aging occurs as a consequence of physical degradation through mechanical abrasion or chemical instability due to $\mathrm{pH}$, temperature and/or enzymes. These are changes over time, but instances of immediate failure have also been reported due to errors in the execution technique of the restoration itself or in the choice and optimal use of the adhesive protocol [6-8].

Evolution of adhesive systems and composite resins has also led to the need of adhesion between two composites. The situations in which this type of adhesion is required are the following:

\section{Repairing procedure of old and infiltrated restorations}

Replacing an old restoration by full removal is often time consuming and expensive [9]. Moreover, this can lead to extra-removal of healthy dental tissue. It is preferable to remove only the affected part of the restoration and then to replace or repair it by adding a new layer of composite [6]. A predictable situation requires a high quality adhesion between the old restoration and the new composite layer [10].

\section{Repairing procedure of broken/fractured veneers orcrowns}

There are often cases of fractured veneers or crowns. Good results are obtained if a proper adhesive protocol is conducted $[9,11]$.

\section{Final restoration after endodontic treatment}

It is often the case that endodontically treated teeth are adhesively restored with composite and the final restoration is performed in another appointment or by another practitioner. In other cases, the final restoration of the teeth that are endodontically treated is made after the pre-endodontic reconstruction of a proximal wall [11]

\section{Cementation procedure of indirect restorations}


Bonded indirect restorations constitute a substantial part of contemporary dentistry. Prosthetic restorations have a weak part which is the resin luting agent layer exposed at the margin [12]. In case of indirect restorations, although it is more desirable that the adhesion takes place on the enamel area, there are cases that require the composite restoration of the proximal walls for the deep margin elevation procedure.

To improve adhesion, the following additional methods are mentioned in literature: surface preparation with different burs, silan-primer application, fluorhydric or ortophosphoric etching, sandblasting with different materials (aluminum oxide powder, glycine powder) [2,13,14]. Sandblasting increases adhesion due to microretentions obtained on the treated surface but it is very important that further etching removes the debris $[11,15]$.

The purpose of this study is to compare three different adhesive protocols used to achieve adhesion between two composites. We tried to simulate clinical situations and achieve the most efficient adhesive protocol. The study was conducted by testing the tensile strength of the two composites.

\section{Materials and methods}

For this in vitro study we used 60 randomly divided composite specimens into 3 equal experimental groups in which adhesion was performed according to different protocols: group 1 $(n=20)$ surface preparation with a diamond bur + etch and rinse technique in 2 steps; group $2(n=20)$ surface preparation with a diamond bur + aluminum oxide sandblasting + etch and rinse technique in 2 steps; group $3(\mathrm{n}=20)$ surface preparation with a diamond bur + glycine sandblasting + etch and rinse technique in 2 steps. Adhesion testing was carried out by measuring tensile strength with a universal testing machine, the Instron 3343 (Instron ${ }^{\circledR}$, USA).

We used a nanohybrid composite, Kerr's Herculite XRV Ultra, color shade A2. The composite specimens were conformed in a plastic mold with the standard dimension of 10x5mm (Figure 3). Using a metal spatula we condensed the composite into the plastic mold. After that, the composites were photopolymerised for $20 \mathrm{~s}$ from 4 different directions (Figure 4). For photopolymerisation the UV Woodpecker LED-B $1200 \mathrm{~mW}$ lamp with a wavelength of 430-485 nm wasused.

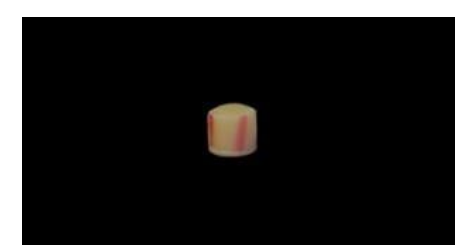

Figure 3. Composite buildup

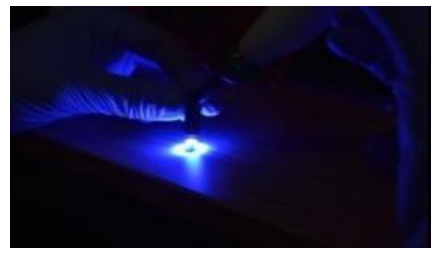

Figure 4. Composite lightcuring

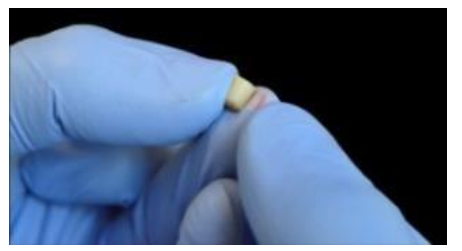

Figure 5. Removal of the plastic mold

The composites were then removed from the plastic mold (Figure 5) and cemented in a metallic conformator in order to fix them in the testing machine. On the hexagonal situs of the conformator horizontal retentions with a $1.4 \mathrm{~mm}$ cylindrical diamond bur were made, Kerr Dental (FG503C-5) (Figure 6). The site was chemically conditioned by applying the pre-hydrolyzed silane primer (ZPrime) from the Duo- Link (Bisco Dental) resin kit (Figure 7). 


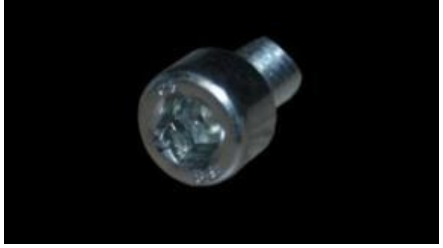

Figure 6. Preparation of the metallic conformator

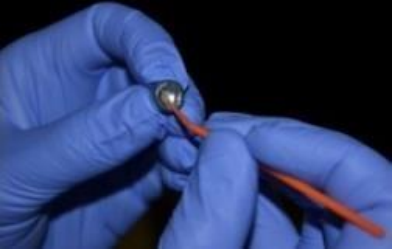

Figure7. Surface conditioning with Z-Prime

Duo-Link dual resin was applied at the site in order to cement the composites. After that a $40 \mathrm{~s}$ photopolymerisation was made. The 60 composite specimens were randomly divided into 3 experimental groups $(n=20)$ in which adhesion was performed according to different protocols.

\section{GROUP 1}

For the first group the adhesive protocol consisted of surface preparation with a medium roughness $1.4 \mathrm{~mm}$ cylindrical diamond bur, Kerr Dental (FG503C-5) (Figure 8) and etch and rinse technique in 2 steps (Figure 9 and Figure10).

The 37\% ortophosphoric etching (Vococid, VOCO) was carried out for $30 \mathrm{~s}$, rinsing for $5 \mathrm{~s}$ and drying for $2 \mathrm{~s}$. The one component light curing adhesivee (All-bond Universal, Bisco) was applied for $20 \mathrm{~s}$, dried for $2 \mathrm{~s}$ and light cured for $20 \mathrm{~s}$.

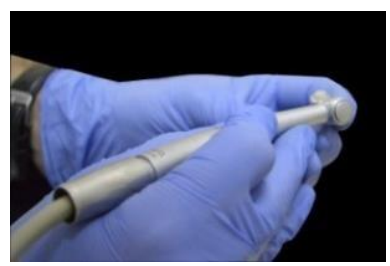

Figure 8.Surface preparation

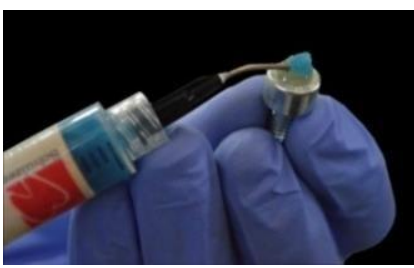

Figure 9. Surface etching

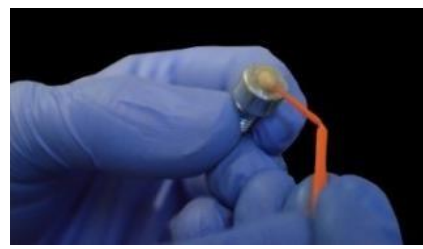

Figure 10. Bonding appliance

\section{GROUP 2}

For group 2, the same surface conditioning was conducted. The difference consisted in adding the aluminum oxide sandblasting step to the adhesive protocol before applying the adhesive system. Sandblasting was done with the air flow device from a $5 \mathrm{~mm}$ distance, for $5 \mathrm{~s}$ and using particles of $105 \mu \mathrm{m}$ from Zhermack Dental.

\section{GROUP 3}

The adhesive protocol for group 3 was similar to the one for group 2 but the composite specimens were sandblasted with glycine. Sandblasting was done with the air flow device from a $5 \mathrm{~mm}$ distance, for 5 seconds and with particles of $25 \mu \mathrm{m}$ from EMS.

After the specimens were prepared, we used the INSTRON 3343 testing machine. The specimens were manually fixed by means of custom accessories.

Using the machine's vertical column, we fixated the specimens in direct contact with each other. After that, the specimens were light cured for $20 \mathrm{~s}$ from 2 different directions (Figure 11). 


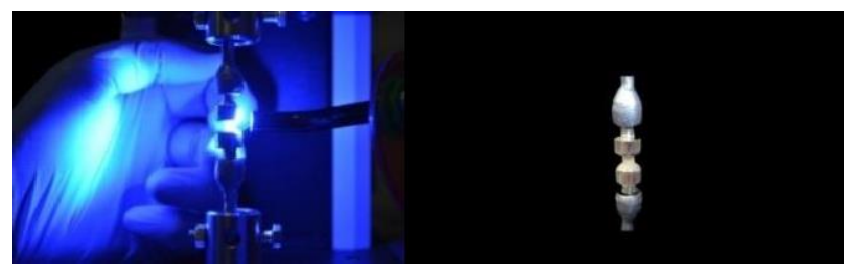

Figure 11. Light curing the composites and the adhesive fixation

We measured the force $(\mathrm{N})$ needed to detach the two specimens using the Bluehill software program (Instron ${ }^{\circledR}$, USA). Testing was done by generating a traction force on the upper arm of the machine. The Bluehill program graphically and numerically recorded the force value $(\mathrm{N})$ (Figure 12) at which two specimens detached from each other (Figure 13).

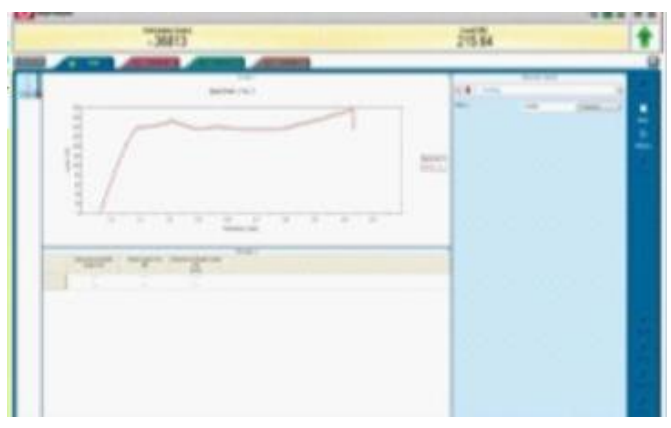

Figure 12.Testing graph

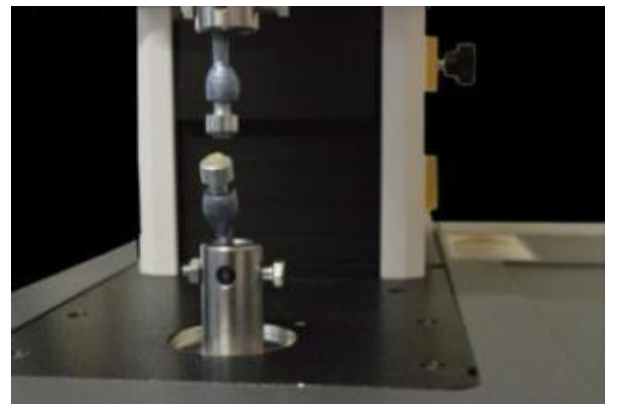

Figure 13. Aspect after detaching

\section{Results and discussions}

Each group was tested to traction for 10 times, and we recorded for each test the value of the force at which the two specimens were detached. We statistically analyzed the values obtained using the One way ANOVA test $(\mathrm{p}<0.05)$, the differences being statistically significant. The values of the forces were directly proportional to the prepared surface as follows: increased values were recorded for sandblasted specimens, the highest mean being recorded by the glycine sandblasted group (group 3) (Graph 1).

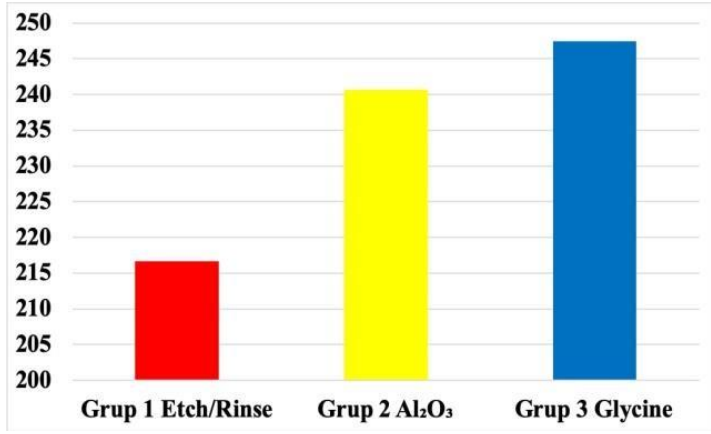

Graph 1. The average of the tensile strength

Group 1 recorded an average of 216,7 N, the values being widely different over the tests. The highest value was $256 \mathrm{~N}$ and the lowest value was $169 \mathrm{~N}$ (Table 1). 
Table 1.Group 1 values for each test

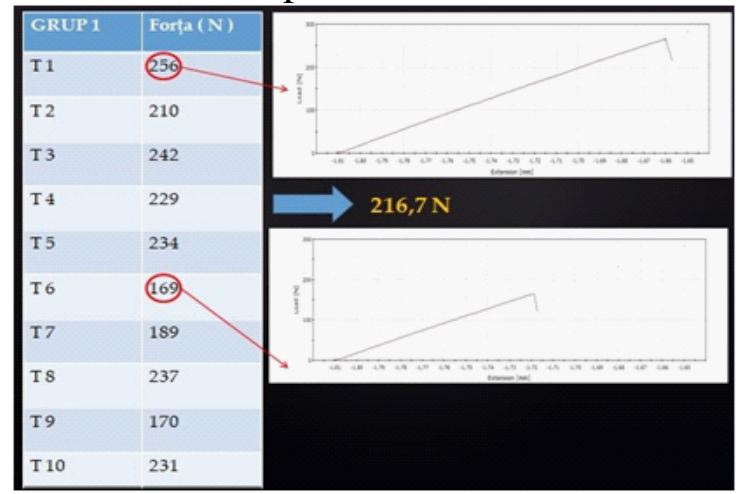

Group 2 recorded an average of 240,7 N. The highest value was $331 \mathrm{~N}$ and the lowest value was 160 $\mathrm{N}$ (Table2).

Table 2. Group 2 values for each test

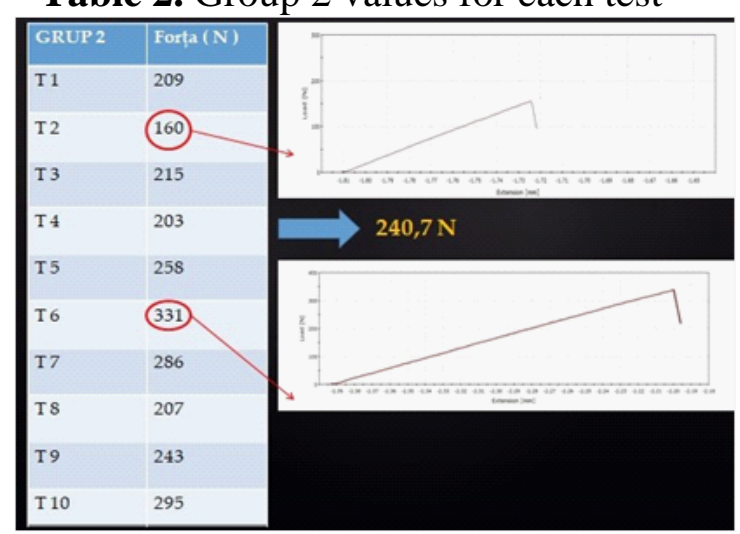

Group 3 recorded an average of 247,5 N. The highest value was $416 \mathrm{~N}$ and the lowest value was $190 \mathrm{~N}$ (Table3).

Table 3. Group 3 values for each test

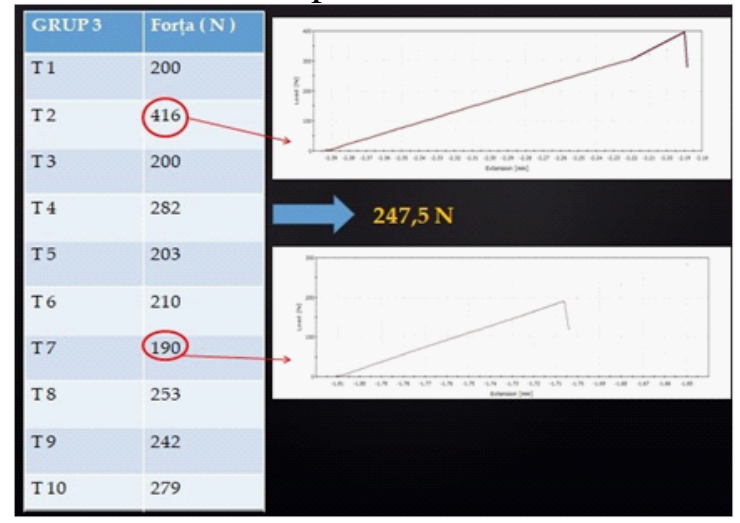

Graphic no 2 shows the behavior of each group for each test, with the values of the traction forces. Each test consisted of 3 study groups. The recorded values depended widely on the parallelism of the tested surfaces and theircompatibility. 


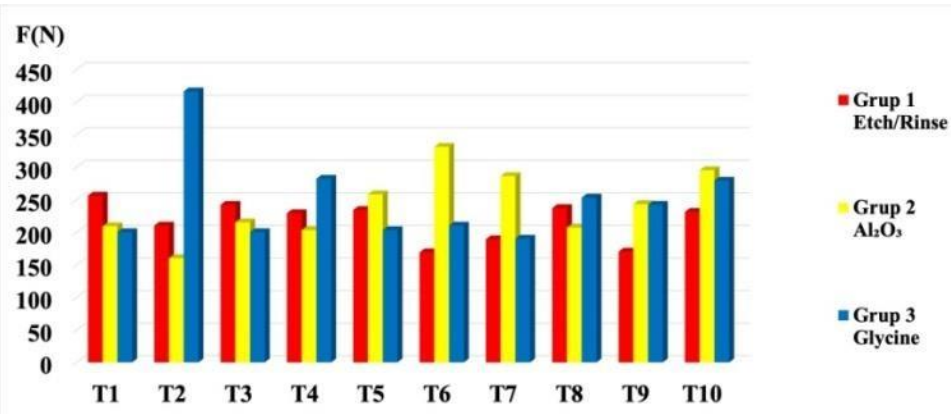

Graph 2. Tensile strength values for all the 3 groups

The study demonstrated the effectiveness of surface preparation by sandblasting, generating adhesion sites for the new resin layer. Furthermore, a better chemical bonding was obtained due to the fact that the monomers of the polymerized resin layer were exposed by sandblasting $[10,15]$.

The study of Ghazaleh and Behnaz, published in march 2016, showed evidence of similar high values in the case of sandblasting groups [16]. They used 75 samples of nanohybrid composite, divided into 5 groups. The study included silanisation, fluorhydric etching, laser conditioning and aluminum oxide sandblasting with a $50 \mu \mathrm{m}$ particle size. The measurement was made by a universal testing machine, the same as the one in ourstudy.

Others studies have demonstrated the efficiency of silane as a bonding agent between two resins. The silane increases adhesion due to its functional groups which generate the connection between the composite and the bonding agent $[4,11]$.

Mechanical treatment of the surface with a diamond bur followed by etching has been acknowledged as an important improvement regarding the adhesive protocol in Tabatabei`s study [17]. The surface was analyzed through SEM and microretentions wereobserved.

The innovation of this study consists in using glycine powder for sandblasting the composites. Glycine is water soluble and has a particle size of under $63 \mu \mathrm{m}$. It is a thinner powder than the aluminum oxide and it protects soft tissues. The quality of microretentions demonstrates the efficiency of this kind of sandblasting $[18,19]$.

A limitation of this study might be the absence of thermocycling and the artificial aging of the composite specimens [20,21] .

\section{Conclusions}

The employed adhesive protocol influenced the adhesion between two composites. The values we obtained were directly proportional with the possibility of creating microretentions on the composite surface.

The sandblasted groups recorded the highest tensile strength values needed to detach the two composite specimens.

The most efficient adhesive protocol was found in the glycine sandblasted group. Glycine demonstrated its properties in this study and its use represents a proven method for better adhesion.

\section{References}

1.MANHART, J., CHEN, H., HAMM, G., HICKEL, R., Buonocore Memorial Lecture. Review of the Clinical Survival of Direct and Indirect Restorations in Posterior Teeth of the Permanent Dentition. Operative Dentistry, 29, 2004, p. 481-508.

2.HAMANO, N., CHIANG, Y.C., NYAMAA, I., YAMAGUCHI, H., INO, S., HICKEL, R., KUNZELMANN, K.H., Effect of different surface treatments on the repair strength of a nanofilled resin-based composite Dental Materials Journal, 30(4), 2011, p.537-545. 
3.RINASTITI, M., OZCAN, M., SISWOMIHARDJO, W., BUSSCHER, H.J., Immediate repair bond strengths of microhybrid, nanohybrid and nanofilled composites after different surface treatments Journal of Dentistry, 38(1), 2010, p.29-38.

4.HICKEL, R., MANHART, J., Longevity of restorations in posterior teeth and reasons for failure Journal of Adhesive Dentistry, 3(1), 2001, p.45-74

5.GAENGLER, P., HOYER, I., MONTAG, R., Clinical evaluation of posterior composite restorations: the 10-year report. Journal of adhesive dentistry Summer, 3(2), 2001, p.185-194.

6.FERNANDEZ, E.M., MARTIN, J.A., ANGEL, P.A., MJOR, I.A., GORDAN, V.V., MONCADA, G.A., Survival rate of sealed, refurbished and repaired defective restorations: 4-Year follow-up Brazilian Dental Journal, 22(2), 2011, p. 134- 139.

7.LOOMANS, B.A., CARDOSO, M.V., ROETERS, F.J., OPDAM, N.J., DE MUNCK, J., HUYSMANS, M.C., VAN MEERBEEK, B., Is there one optimal repair technique for all composites? Dental Materials, 27(7), 2011, p.701-709.

8.ROULET, J.F., Degradation of Dental Polymers Karger, 1987, Basel, Switzerland.

9.SARACOGLU, A., OZCAN, M., KUMBULOGLU, O., TURKUN, M., Adhesion of resin composite to hydrofluoric acid exposed enamel and dentin in repair protocols Operative Dentistry, 36(5), 2011, p.545-553.

10.RINASTITI, M., ÖZCAN, M., SISWOMIHARDJO, W., BUSSCHER, H.J., Effects of surface conditioning on repair bond strengths of non-aged and aged microhybrid, nanohybrid, and nanofilled composite resins. Clin Oral Invest, 15, 2011, p. 625-633.

11.LUCENA-MARTÍN, C., GONZÁLEZ-LÓPEZ, S., NAVAJAS-RODRÍGUEZ DE MONDELO, J.M., The effect of various surface treatments and bonding agents onthe repaired strength of heattreated composites. J Prosthet Dent, 86, 2011, p. 481-488.

12.POPA, D., CONSTANTINIUC, M., CAMPIAN R.S., STUDIA UBB CHEMIA, LXI, 2, 2016, p.261-281.

13.OZCAN, M., BARBOSA, S.H., MELO, R.M., GALHANO, G.A., BOTTINO, M.A., Effect of surface conditioning methods on the microtensile bond strength of resin composite to composite after aging conditions. Dental Materials, 2007, p. 1276-1282.

14.ÖZCAN, M., PEKKAN, G., Effect of different adhesion strategies on bond strength of resin composite to composite-dentin complex. Oper Dent., 2013, p. 63-72.

15.CAVAlCANTI, A.N., LAVIGNE, C., FONTES, C.M., MATHIAS, P., Microleakage at the composite-repair interface: effect of different adhesive systems. J Appl Oral Sci., 2004, p.219-222

16.GHAZALEH, A., BEHNAZ, E., ARNICA, T., ZAHRA, J., TOLOO, J., FARSHID, A., DANEHSVAR, K., SORAYA, K., Effect of different surface treatments on the shear bond strength of nanofilled composite repairs, 16 mar. 2016.

17.HASANI, T.M., ALIZADE, Y., TAALIM, S., Effect of various surface treatment on repair strength of composite resin. J Dent TUMS.,2004, p.5-11.

18.GIACOMELli, L., SALERNO, M., DERCHI, G., GENOVESI, A., PAGANIN, P.P., COVANI, U., Effect of air polishing with glycine and bicarbonate powders on nanocomposite used in dental restorations: An in vitro study. Int J Periodontics Restorative Dent., 2001, p.51-56.

19.SARAH, J.G., MICHELLE, L.S., JILL L.S., Air polishing: A review of current literature, aug2013. 20.ORTENGREN, U., WELLENDORF, H., KARLSSON, S., RUYTER, I.E., Water sorption and solubility of dental composites and identification of monomers released in an aqueous environment Journal of Oral Rehabilitation, 28(12), 2001, p. 1106- 1115.

21.SODERHOLM, K.J., MUKHERJEE, R., LONGMATE, J., Filler leachibility of composite stored in distilled water or artificial saliva Journal of Dental Research, 75(9), 1996, p.1692-1699.

$\overline{\text { Manuscript received: } 18.12 .2019}$ 